\title{
Alkanediyl- $\alpha, \omega$-bis (Dimethyl Cetylammonium Bromide) Gemini Surfactants as Novel Corrosion Inhibitors for Mild Steel in Formic Acid
}

\author{
Mohammad Mobin*, Sheerin Masroor \\ Corrosion Research Laboratory, Department of Applied Chemistry, Faculty of Engineering and Technology, \\ Aligarh Muslim University, U.P. 202002, Aligarh, India
}

Received: December 12, 2011; Revised: May 14, 2012

\begin{abstract}
Gemini surfactants, butanediyl 1,4-bis(dimethyl cetylammonium bromide), pentanediyl 1,5 - bis (dimethyl cetylammonium bromide) and hexanediyl 1,6 - bis (dimethyl cetylammonium bromide) from Alkanediyl- $\alpha, \omega$-bis (dimethyl cetylammonium bromide) series were synthesized in laboratory and were characterized by using Nuclear Magnetic Resonance (NMR) spectroscopy. The surfactants were tested as corrosion inhibitors for mild steel in $20 \%$ formic acid. The influence of surfactants on mild steel corrosion inhibition was investigated by measuring the corrosion rate of mild steel in their absence and presence by weight loss measurements, solvent analysis of iron ions into the test solution and potentiodynamic polarization measurements. The surface morphology of the corroded steel samples in presence and absence of surfactants was evaluated by using Scanning Electron Microscopy (SEM). The synthesized gemini surfactants performed as excellent corrosion inhibitor, the inhibition efficiency (IE) being in the range of 76.66-97.41\%. The IE of surfactants is slightly affected by the spacer length. The IE increased with increase in surfactant concentration and temperature. The adsorption of gemini surfactants on the steel surface was found to obey Langmuir adsorption isotherm. The results of the potentiodynamic polarization studies are consistent with the results of weight loss studies.
\end{abstract}

Keywords: gemini surfactant, corrosion inhibitor, mild steel, weight loss measurements, potentiodynamic polarization measurements

\section{Introduction}

The use of corrosion inhibitors for metals protection is one of the practically acclaimed methods, especially in acid media ${ }^{1,2}$. Most of the inhibitors used in the industries are organic compounds containing nitrogen, sulphur, and/or oxygen atoms in their structure. The inhibitor molecules are physically or chemically adsorbed on the corroding metal surface forming a protective layer and isolating it from aggressive medium ${ }^{3-12}$. Limited numbers of references are available dealing with corrosion studies of metals in organic acids ${ }^{13-15}$. Organic acids, which constitute a group of important chemicals currently used in chemical industries, find use in preparation of chemicals, drugs, plastic and fibers. Organic acids, though weak acids provide sufficient protons to act as true acids towards most metals ${ }^{16}$. The strength of organic acids tends to decrease with increase in molecular weight. This makes a low molecular weight formic acid quite corrosive. The surfactants have a remarkable ability of influencing the surfaces and interfaces. They have been used as corrosion inhibitors either alone or in combination with other compounds to improve their performance as inhibitors ${ }^{17-21}$. The surfactant molecules possess strong adsorption ability to the metallic surfaces. The intrinsic ability of the molecules to easily adsorb on surfaces and interfaces is associated with their amphiphillic structure. The adsorption process depends upon the structure and concentration of surfactant molecules in the contacting

*e-mail: drmmobin@hotmail.com medium $^{22}$. The adsorbed surfactant molecules form a monolayer or bilayer hemimicelles or admicelles and prevent the acids to attack the surface, and thus reduce the corrosion $^{23-26}$. In recent years, a new class of surfactants called gemini or dimeric surfactants have attracted great attention in corrosion inhibition ${ }^{27-29}$. The gemini surfactants contains two hydrophilic and two hydrophobic (sometimes three) groups per molecule separated by a rigid or flexible spacer rather than one hydrophilic and one hydrophobic group for conventional surfactants. They are more efficient in reducing the surface tension and forming micelles than conventional surfactant.

The present work was undertaken to investigate the corrosion inhibition of mild steel in $20 \%$ formic acid using three novel gemini surfactants from the series Alkane diyl $\alpha$, $\omega$-bis(dimethyl cetylammonium bromide). They are butane diyl-1,4-bis(dimethyl cetylammonium bromide), pentane diyl-1,5-bis (dimethyl cetylammonium bromide), hexane diyl-1,5-bis (dimethyl cetylammonium bromide) (referred as $\mathrm{BDAB}, \mathrm{PDAB}$, and $\mathrm{HDAB}$ respectively, in this paper).

\section{Experimental Procedures}

\subsection{Material preparation}

The mild steel coupons having composition $0.194 \% \mathrm{C}$, $0.176 \% \mathrm{Mn}, 0.0103 \% \mathrm{P}, 0.059 \% \mathrm{~Pb}, 0.014 \% \mathrm{Al}, 0.034 \% \mathrm{~V}$ and balance $\mathrm{Fe}$ were used for corrosion inhibition studies. 
The mild steel sheets were mechanically press-cut into coupons of dimension $2.0 \times 2.0 \times 0.04 \mathrm{~cm}$. The coupons were machined and abraded on different grades emery papers, washed with double distilled water (DDW), degreased with absolute ethanol and finally dried in acetone. A hole of $1 \mathrm{~mm}$ diameter was made near the edge of the specimen for hooking. The treated coupons were then stored in moisture-free desiccators before their use in corrosion inhibition studies. The solution of $20 \%$ formic acid was prepared by using AR grade formic acid (Qualigens) and DDW. The gemini surfactants were synthesized in laboratory following an identical synthesis route described earlier ${ }^{30,31}$. The names and molecular structures of the synthesized compounds are given in Table 1.

\subsection{Characterization of gemini surfactants}

To investigate the purity, the synthesized gemini surfactants were characterized using NMR technique. ${ }^{1} \mathrm{H}$ NMR spectra of the compounds were obtained in $\mathrm{CDCl}_{3}$ using a BRUKER DRX-300 NMR spectrometer operated at $300.13 \mathrm{MHz}$.

\subsection{Weight loss measurements}

The weight loss experiments were performed for duration of 6 hours as per American Standard for Testing Materials (ASTM) designation G1-90. The cleaned mild steel coupons were suspended in $250 \mathrm{~mL}$ beakers containing $200 \mathrm{~mL}$ of test solutions maintained at $30-60{ }^{\circ} \mathrm{C}$ in a temperature controlled water bath. The concentration of inhibitors in $20 \%$ formic acid was kept between $1.0 \times 10^{-3}$ to $1.0 \times 10^{-5} \mathrm{M}$. The observed weight loss was the difference between the weight at a given time and the original weight of the coupons. The measurements were carried out for the uninhibited solution (blank) and solutions containing inhibitor. The corrosion rates (CR) were determined using the Equation 1:

Corrosion rate $(C R)(\mathrm{mpy})=\frac{534 \mathrm{~W}}{\rho A t}$

where $W$ is weight loss in $\mathrm{mg} ; \rho$ is the density of specimen in $\mathrm{g} . \mathrm{cm}^{-3} ; A$ is the area of specimen in square inch and $\mathrm{t}$ is exposure time in hours. The inhibition efficiency (\%IE) of the Gemini surfactants was evaluated using the following Equation 2:
$(\% \mathrm{IE})=\frac{\mathrm{CRo}-\mathrm{CRi}}{\mathrm{CRo}} \times 100$

where, CRo is the Corrosion rate of mild steel in absence of surfactant and CRi is corrosion rate of mild steel in presence of surfactant.

\subsection{Solution analysis of metal ions}

The corrosion rate and inhibition efficiency of mild steel was also investigated from the determination of total iron ions $\left(\mathrm{Fe}^{2+} / \mathrm{Fe}^{3+}\right)$ entered into the test solution during the course of immersion. The analysis was performed spectrophotometrically ${ }^{32-33}$ using Elico-SL-169 UV-visible spectrophotometer. The corrosion rate was calculated using the following relationship (Equation 3):

Corrosion rate $(C R)\left(\mathrm{g} / \mathrm{m}^{2} \mathrm{~h}\right)=\frac{m}{\mathrm{~s} \times t}$

where $\mathrm{m}$ is the mass of corroded metal (calculated from the total iron content determined in the test solution); $\mathrm{s}$ is the area of the test metal in $\mathrm{m}^{2}$; and $\mathrm{t}$ is the exposure time in hours. The \% IE of the compounds was evaluated using Equation 2.

\subsection{Electrochemical polarization method}

The potentiodynamic polarization measurements were carried out on Micro Autolab type III potentiostat/Galvanostat (Model: $\mu 3$ AVT 70762, Netherlands) with saturated calomel electrode (SCE) as reference and Pt wire as counter electrode. The potentiodynamic polarization measurements were performed by sweeping the potential between -0.25 and $0.25 \mathrm{~V}$ from open circuit potential at a scan rate of $0.0005 \mathrm{~V} / \mathrm{s}$. The specimen was allowed to stabilize in the electrolyte for 30 minutes prior to the experiment. All the experiments were done at room temperature.

\subsection{Scanning electron microscopy}

The surface morphology of mild steel specimens immersed in uninhibited and inhibited acid solution was evaluated using SEM technique (Model: LEO 430, Cambridge England). To study the surface morphology the freshly prepared samples were thoroughly washed with DDW. The photographs were captured from that portion of sample from where better information can be obtained. The specimen were photographed at appropriate magnifications $(2000-5000 \mu \mathrm{m})$.To understand the effect of inhibitors on

Table 1. Name and molecular structure of gemini surfactants.

\begin{tabular}{|c|c|c|}
\hline S. No. & Molecular structure & Name and abbreviation \\
\hline 1 & $\begin{array}{cc}\mathrm{CH}_{3} & \mathrm{CH}_{3} \\
\mathrm{CH}_{3}-\left(\mathrm{CH}_{2}\right)_{15}-\mathrm{I}_{\mathrm{N}}^{\mathrm{N}^{+}}-\mathrm{CH}_{2}-\mathrm{CH}_{2}-\mathrm{CH}_{2}-\mathrm{CH}_{2}-\underset{\mathrm{N}^{+}}{\mathrm{N}_{2}}-\left(\mathrm{CH}_{2}\right)_{15}-\mathrm{CH}_{3} 2 \mathrm{Br}- \\
\mathrm{CH}_{3} & \mathrm{CH}_{3}\end{array}$ & $\begin{array}{c}\text { Butane diyl 1,4-bis (dimethyl cetylammonium } \\
\text { bromide) (BDAB) }\end{array}$ \\
\hline 2 & $\begin{array}{cc}\mathrm{CH}_{3} & \mathrm{CH}_{3} \\
\mathrm{CH}_{3}-\left(\mathrm{CH}_{2}\right)_{15}-\mathrm{N}^{+}-\mathrm{CH}_{2}-\mathrm{CH}_{2}-\mathrm{CH}_{2}-\mathrm{CH}_{2}-\mathrm{CH}_{2}-\mathrm{N}^{+}-\left(\mathrm{CH}_{2}\right)_{15}-\mathrm{CH}_{3} 2 \mathrm{Br} & \mathrm{I} \\
\mathrm{CH}_{3} & \mathrm{CH}_{3}\end{array}$ & $\begin{array}{c}\text { Pentane diyl 1,5-bis (dimethylcetyl ammonium } \\
\text { bromide) (PDAB) }\end{array}$ \\
\hline 3 & $\begin{array}{cc}\mathrm{CH}_{3} & \mathrm{CH}_{3} \\
\mathrm{CH}_{3}-\left(\mathrm{CH}_{2}\right)_{15}-\mathrm{N}^{++}-\mathrm{CH}_{2}-\mathrm{CH}_{2}-\mathrm{CH}_{2}-\mathrm{CH}_{2}-\mathrm{CH}_{2}-\mathrm{CH}_{2}-\mathrm{N}^{+}-\left(\mathrm{CH}_{2}\right)_{15}-\mathrm{CH}_{3} 2 \mathrm{Br}^{-} \\
\mathrm{CH}_{3} & \mathrm{CH}_{3}\end{array}$ & $\begin{array}{c}\text { Hexane diyl 1,6-bis (dimethyl cetylammonium } \\
\text { bromide (HDAB) }\end{array}$ \\
\hline
\end{tabular}


the morphology of steel surface the following steel sample were examined under SEM.

- Polished mild steel sample;

- Mild steel sample dipped in $20 \%$ formic acid for 6 hours;

- Mild steel sample dipped in $20 \%$ formic acid containing $5 \times 10^{-4} \mathrm{M}$ BDAB;

- Mild steel sample dipped in $20 \%$ formic acid containing $5 \times 10^{-4} \mathrm{M}$ PDAB; and

- Mild steel sample dipped in $20 \%$ formic acid containing $5 \times 10^{-4} \mathrm{M}$ HDAB.

\section{Results and Discussion}

\subsection{Characterization of gemini surfactants}

The synthesized Gemini surfactants were characterized using ${ }^{1} \mathrm{H}$ NMR technique. The pertinent details of NMR of the synthesized gemini surfactants are as follows (Figure 1).
Butane diyl 1,4-bis (dimethyl cetylammonium bromide) (BDAB): $\left.{ }^{1} \mathrm{HNMR}(300 \mathrm{MHz}), \mathrm{CDCl}_{3}\right) \delta 0.88(\mathrm{t}, 6 \mathrm{H}$, alkyl chain $2 \times 1 \mathrm{CH}_{3}$ ), 1.256-1.351 (br m, $44 \mathrm{H}$, alkyl chain $2 \times 11 \mathrm{CH}_{2}$ ), $1.757\left(\mathrm{~m}, 12 \mathrm{H}\right.$, alkyl chain $\left.2 \times 3 \mathrm{CH}_{2}\right), 2.084$ (br s, $4 \mathrm{H}$, spacer chain $\left.1 \times 2 \mathrm{CH}_{2} \mathrm{CH}_{2} \mathrm{~N}^{+}\right), 3.320\left(\mathrm{~s}, 12 \mathrm{H}, 2 \times 2 \mathrm{~N}^{+} \mathrm{CH}_{3}\right)$, 3.432-3.453 (m, $4 \mathrm{H}$, alkyl chain $\left.2 \times 1 \mathrm{CH}_{2} \mathrm{~N}^{+}\right), 3.828$ (br s, $4 \mathrm{H}$, spacer chain $2 \times 1 \mathrm{CH}_{2} \mathrm{~N}^{+}$).

Pentane diyl 1,5-bis (dimethyl cetylammonium bromide) (PDAB): ${ }^{1} \mathrm{H}$ NMR (300 MHz), $\left.\mathrm{CDCl}_{3}\right) \delta 0.88(\mathrm{t}, 6 \mathrm{H}$, alkyl chain $2 \times 1 \mathrm{CH}_{3}$ ), 1.257-1.357 (br m, $42 \mathrm{H}$, alkyl chain $2 \times 10 \mathrm{CH}_{2}$ and spacer chain $\left.1 \mathrm{CH}_{2}\right), 1.597-1.734$ (crude t, $16 \mathrm{H}$, alkyl chain $2 \times 4 \mathrm{CH}_{2}$ ), 2.050 (br m, $4 \mathrm{H}$, spacer chain $\left.1 \times 2 \mathrm{CH}_{2} \mathrm{CH}_{2} \mathrm{~N}^{+}\right), 3.377\left(\mathrm{~s}, 12 \mathrm{H}, 2 \times 2 \mathrm{~N}^{+} \mathrm{CH}_{3}\right), 3.521$ (crude t, $4 \mathrm{H}$, alkyl chain $2 \times 1 \mathrm{CH}_{2} \mathrm{~N}^{+}$), 3.804 (crude t, $4 \mathrm{H}$, spacer chain $1 \times 2 \mathrm{CH}_{2} \mathrm{~N}^{+}$).

Hexane diyl 1,5-bis (dimethyl cetylammonium bromide) (HDAB): ${ }^{1} \mathrm{H}$ NMR (300 MHz), $\left.\mathrm{CDCl}_{3}\right) \delta 0.88(\mathrm{t}, 6 \mathrm{H}$, alkyl chain $\left.2 \times 1 \mathrm{CH}_{3}\right), 1.255-1.350(\mathrm{~s}+\mathrm{br} \mathrm{m}, 48 \mathrm{H}$, alkyl chain $2 \times 12 \mathrm{CH}_{2}$ ), 1.560-1.721 (br m, $12 \mathrm{H}$, spacer chain $1 \times 2 \mathrm{CH}_{2} \mathrm{CH}_{2} \mathrm{~N}^{+}$and alkyl chain $2 \times 1 \mathrm{CH}_{2} \mathrm{CH}_{2} \mathrm{CH}_{2} \mathrm{~N}^{+}$, ,

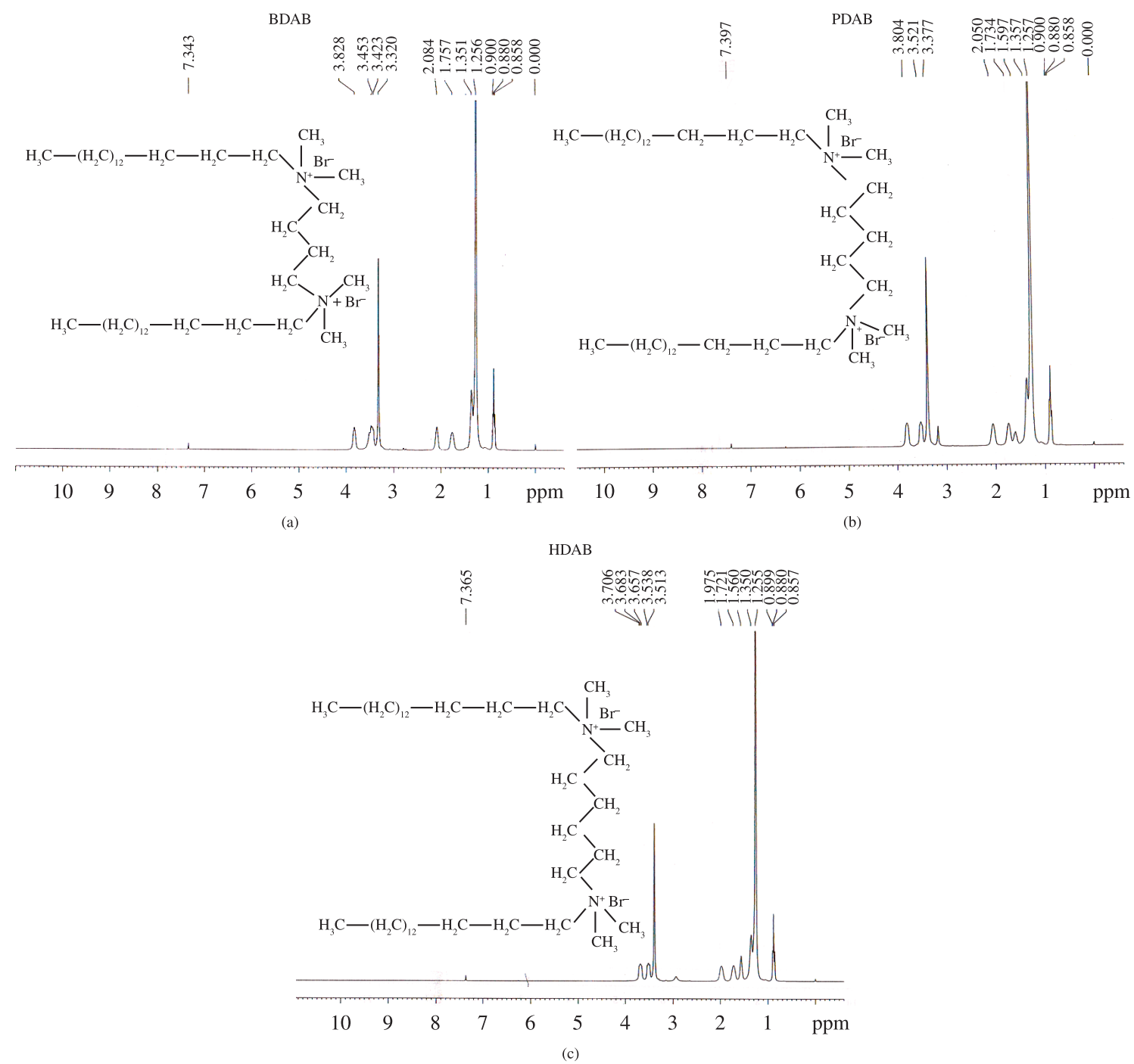

Figure 1. Nuclear Magnetic Resonance (NMR) Spectra of the synthesized gemini surfactants and their molecular structure a) BDAB, b) PDAB, c) HDAB. 
1.975 (br s, $4 \mathrm{H}$, spacer chain $1 \times 2 \mathrm{CH}_{2} \mathrm{CH}_{2} \mathrm{CH}_{2} \mathrm{~N}^{+}$), 3.513-3.538 (br s, $16 \mathrm{H}, 2 \times 2 \mathrm{~N}^{+} \mathrm{CH}_{3}$ alkyl chain $2 \times 1 \mathrm{CH}_{2} \mathrm{~N}^{+}$), 3.657-3.706 (m, $4 \mathrm{H}$, spacer chain $\left.1 \times 2 \mathrm{CH}_{2} \mathrm{~N}^{+}\right)$.

\subsection{Weight loss measurements}

The corrosion inhibition of mild steel in $20 \%$ formic acid at $30-60{ }^{\circ} \mathrm{C}$ in absence and presence of different concentrations of gemini surfactants was studied using weight loss technique. The corrosion rate is reduced in presence of all the three gemini surfactants as compared to the free acid solution (Table 2). Also the corrosion rate increased with increase in temperature at all concentrations studied. The plot of $\% \mathrm{IE}$ as a function of concentrations of the compounds at $30-60{ }^{\circ} \mathrm{C}$ (Figure 2) reveals that at given temperature the IE only slightly increases with increase in surfactant concentrations. However, the effect of temperature on IE is quite pronounced, the IE increases with increase in temperature.

The inhibition of mild steel corrosion by gemini surfactants can be explained in terms of its adsorption on the steel surface. The adsorption mechanism of gemini surfactants on steel surface is quite different from that of conventional single chained surfactants. The adsorption behavior is more complicated than the conventional surfactants as they contain two hydrophilic and two hydrophobic groups. Like conventional surfactants, in case of gemini surfactants also multilayer may form at surfactant concentration above critical micelle concentrate (CMC). However, before multilayer may form three different situations may be visualized ${ }^{34}$. In first situation two hydrophilic ionic groups of gemini surfactant may be adsorbed on the metal surface. In second situation one hydrophilic ionic group is adsorbed on the surface whereas the second hydrophilic ionic group is free in the solution phase. Thirdly, both the situation may coexist. At lower concentration of the gemini surfactants the main adsorption mechanism is governed by the first situation. At high concentration adsorption mechanism is governed by the second situation but the third situation appears to be more reasonable because of the interaction between the molecules of gemini surfactants. Considering the result of the present investigation, in general, all the three gemini surfactants used during the investigation showed excellent $\%$ IE at their CMC which is in the range of 3.5-4.6 $\times 10^{-5} \mathrm{M}$ at $30^{\circ} \mathrm{C}$. The excellent IE of the compounds is due to high degree of surface coverage resulting from their adsorption on the steel surface. The strong adsorption in case of double chained gemini surfactants can be explained on the basis of electrostatic interaction between the two ammonium groups and the cathodic sites on the steel surface. Below CMC as the surfactants concentration increases, the molecules tend to aggregate at the interface and the interfacial aggregation reduces the surface tension. On further increase in the surfactant concentration above CMC more molecules are adsorbed around the initially adsorbed molecules by hydrophobic interaction and finally form the surface aggregates. This consequently does not alter the surface tension and the corrosion rate and hence the IE. The comparison of the corrosion performance of three surfactants showed that BDAB has slightly higher values of IE than other surfactants. This may be due to the fact that though all the three surfactants have same geometric length of the hydrophobic chain $\left(\mathrm{C}_{16}\right)$ but have different spacer length. A slightly higher IE of BDAB might be due to its smaller

Table 2. Corrosion parameters for mild steel in $20 \%$ formic acid in absence and presence of the gemini surfactants from weight loss measurements at different temperatures.

\begin{tabular}{|c|c|c|c|c|c|c|c|c|}
\hline \multirow{2}{*}{$\begin{array}{c}\text { Surfactant } \\
\text { concentration } \\
\text { (M) }\end{array}$} & \multicolumn{4}{|c|}{ Corrosion rate (mpy) } & \multicolumn{4}{|c|}{ Inhibition Efficiency (IE) } \\
\hline & $30^{\circ} \mathrm{C}$ & $40{ }^{\circ} \mathrm{C}$ & $50{ }^{\circ} \mathbf{C}$ & $60^{\circ} \mathrm{C}$ & $30^{\circ} \mathrm{C}$ & $40{ }^{\circ} \mathrm{C}$ & $50{ }^{\circ} \mathbf{C}$ & $60^{\circ} \mathrm{C}$ \\
\hline Blank & 415 & 1556.64 & 2879.16 & 5091.84 & - & - & - & - \\
\hline \multicolumn{9}{|l|}{$\mathrm{BDAB}$} \\
\hline $1 \times 10^{-5}$ & 74.15 & 113.99 & 154.04 & 200.86 & 82.13 & 92.68 & 92.69 & 96.06 \\
\hline $5 \times 10^{-5}$ & 60.96 & 109.11 & 141.06 & 181.69 & 85.31 & 92.99 & 94.64 & 96.43 \\
\hline $1 \times 10^{-4}$ & 61.03 & 100.08 & 121.20 & 171.05 & 85.29 & 93.57 & 95.10 & 96.64 \\
\hline $5 \times 10^{-4}$ & 51.95 & 93.03 & 109.73 & 133.74 & 87.48 & 94.02 & 96.19 & 97.37 \\
\hline $1 \times 10^{-3}$ & 63.24 & 111.93 & 210.29 & 131.75 & 84.76 & 92.81 & 92.69 & 97.41 \\
\hline \multicolumn{9}{|l|}{ PDAB } \\
\hline $1 \times 10^{-5}$ & 95.71 & 128.16 & 178.22 & 227.72 & 76.94 & 93.81 & 93.81 & 95.52 \\
\hline $5 \times 10^{-5}$ & 96.86 & 109.01 & 145.35 & 197.18 & 76.66 & 92.99 & 94.95 & 96.13 \\
\hline $1 \times 10^{-4}$ & 92.05 & 116.48 & 134.06 & 178.73 & 77.81 & 92.52 & 95.34 & 96.48 \\
\hline $5 \times 10^{-4}$ & 77.91 & 105.21 & 133.48 & 156.71 & 81.22 & 93.24 & 95.36 & 96.92 \\
\hline $1 \times 10^{-3}$ & 77.57 & 109.02 & 127.70 & 284.56 & 81.31 & 92.99 & 95.56 & 94.41 \\
\hline \multicolumn{9}{|l|}{ HDAB } \\
\hline $1 \times 10^{-5}$ & 64.19 & 119.35 & 161.82 & 236.65 & 84.53 & 92.33 & 94.38 & 95.35 \\
\hline $5 \times 10^{-5}$ & 72.68 & 109.66 & 162.47 & 232.38 & 82.49 & 92.96 & 94.35 & 95.44 \\
\hline $1 \times 10^{-4}$ & 72.92 & 110.40 & 147.85 & 203.84 & 82.43 & 92.91 & 94.86 & 95.99 \\
\hline $5 \times 10^{-4}$ & 64.29 & 95.46 & 123.79 & 180.83 & 84.51 & 93.86 & 95.70 & 96.45 \\
\hline $1 \times 10^{-3}$ & 61.72 & 113.18 & 123.55 & 156.62 & 85.13 & 92.73 & 95.71 & 96.92 \\
\hline
\end{tabular}


spacer size. A smaller spacer size means shorter distance between the two head groups in unit gemini molecule, thereby enhancing the charge density of head groups and favoring the adsorption of surfactant ${ }^{35}$. Considering the effect of temperature on inhibition behavior of gemini surfactants, the IE also increases with increase in temperature. This pointed to the capability of surfactants to inhibit corrosion of steel at low and relatively high temperatures. The gemini surfactants on steel surface are chemically adsorbed on to the mild steel surface which is less favored at lower temperature due to high kinetic energy barrier.

\subsection{Adsorption isotherm}

The mechanism of corrosion inhibition can be explained on the basis of adsorption behavior of the inhibitors on the metal surface. The adsorption of organic compounds

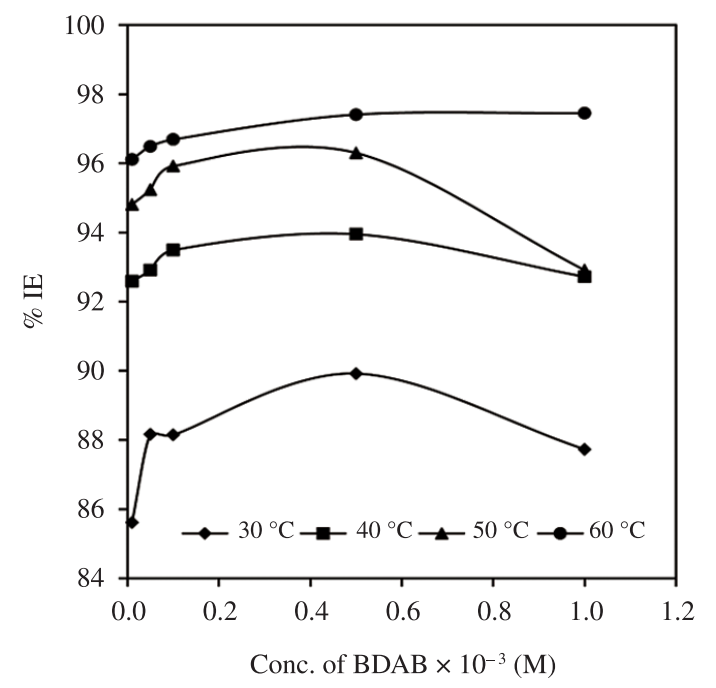

(a)

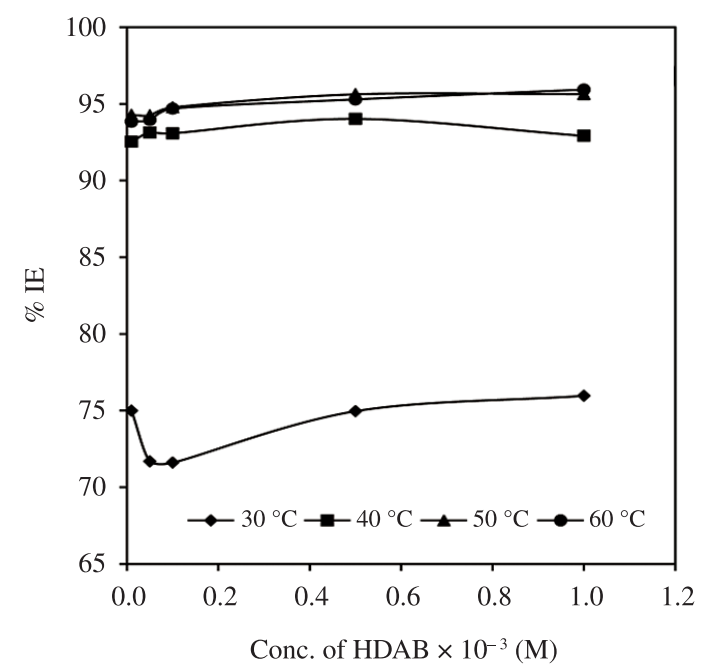

(c) on the metal surfaces can be described by two main types of interactions namely, physical adsorption and chemical adsorption. These adsorptions are dependent on the electronic structure of the metal, the nature of the electrolyte and the chemical structure of the organic compounds. An inspection of plots of surfactants concentration against $\%$ IE at different temperatures revealed that IE increases with increase in surfactants concentration and temperature which is suggestive of chemical adsorption mechanism. The character of adsorption of gemini surfactants was elucidated from the values of degree of surface coverage $(\theta)$ calculated from the weight loss data. Attempts were made to fit the $\theta$ values to various adsorption isotherms but best results were obtained for Langmuir adsorption isotherm. The plots of $\mathrm{C} / \theta$ against $\mathrm{C}$ were drawn which is characteristics of Langmuir adsorption isotherm given by Equation 4:

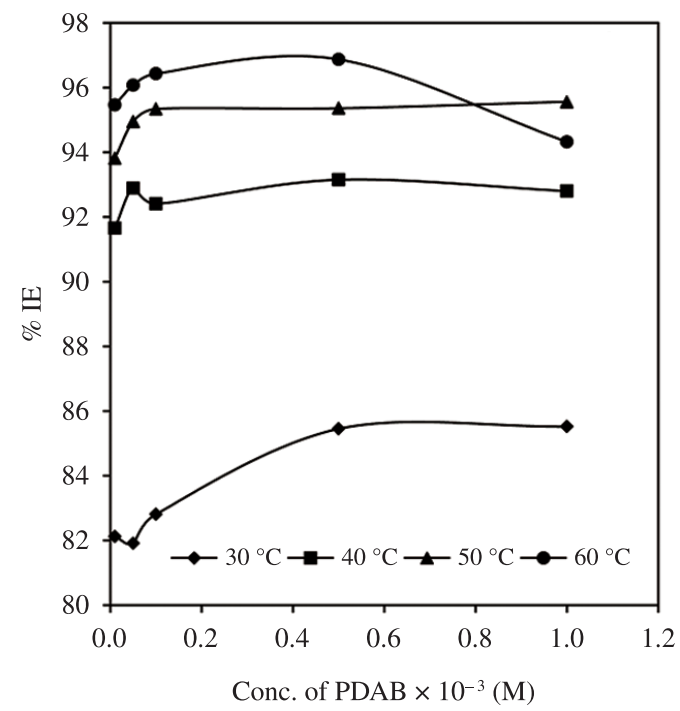

(b)

Figure 2. Plot of inhibition efficiency (\%IE) vs. Concentration for mild steel in $20 \%$ formic acid with a) BDAB, b) PDAB, and c) HDAB at different temperatures. 
$\frac{\mathrm{C}}{\theta}=\frac{1}{\mathrm{k}}+\mathrm{C}$

where $\theta$ is the degree of surface coverage, $\mathrm{k}$ is the equilibrium constant of the adsorption process and $\mathrm{C}$ is the inhibitor concentration. The plots of $\mathrm{C} / \theta$ versus $\mathrm{C}$ for mild steel corrosion in $20 \%$ formic acid for the three gemini surfactants at temperatures $30-60{ }^{\circ} \mathrm{C}$ are shown in Figure 3 . A linear correlation of slope close to unity suggests that the adsorption of these surfactants on mild steel interface obeys Langmuir adsorption isotherm at all the temperatures studied. The equilibrium constant $\mathrm{K}$, denotes the strength between the adsorbate and adsorbant. Large values of $\mathrm{K}$ imply more efficient adsorption and hence better inhibition efficiency ${ }^{36}$. K values are seen to increase with increase in temperature suggesting that the surfactants inhibitors are chemically adsorbed onto the mild steel surface. The values of $\mathrm{K}$ and $\mathrm{R}^{2}$ are given in Table 3 .

\subsection{Effect of temperature}

The corrosion of mild steel in $20 \%$ formic acid was studied in the temperature range of $30-60{ }^{\circ} \mathrm{C}$ in the absence and presence of gemini surfactants. A plot for logarithm of corrosion rate $(\log \mathrm{CR})$ versus reciprocal of absolute temperature $(1 / \mathrm{T})$ is presented in Figure 4. Linear plot was obtained which indicates that it follows Arrhenius Equation $5^{[20]}$.

$\log \mathrm{CR}=\log \mathrm{A}-\frac{\mathrm{E}_{\mathrm{a}}}{2.303 \mathrm{RT}}$

where $\mathrm{CR}$ is the corrosion rate, $\mathrm{A}$ is the Arrhenius constant, $\mathrm{E}_{\mathrm{a}}$ is the apparent activation energy, $\mathrm{R}$ is the molar gas constant and $\mathrm{T}$ is the absolute temperature. The values of $\mathrm{E}_{\mathrm{a}}$ obtained from the slope of the linear plot are presented in Table 4. A decrease in $\mathrm{E}_{\mathrm{a}}$ values in presence of the gemini surfactants compared to the blank indicates an increase in the adsorption process of the surfactants on the mild steel surface with rise in temperature (chemisorption). The

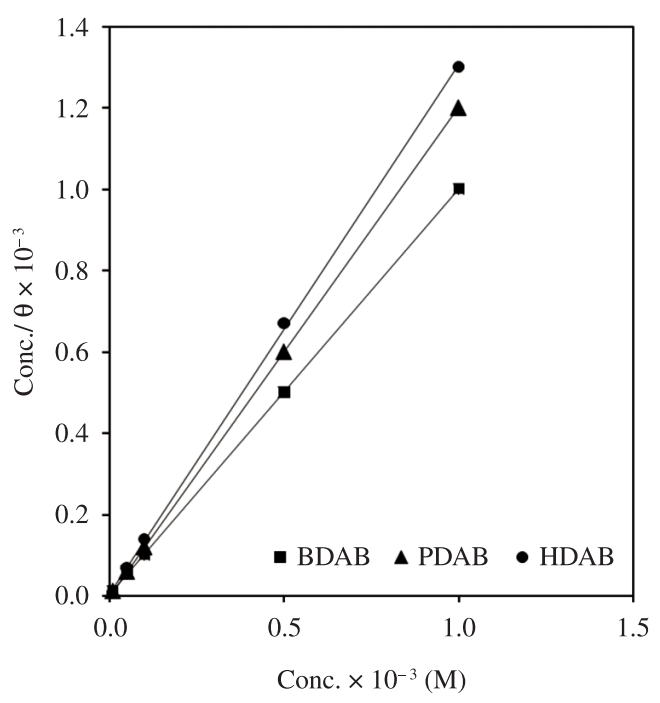

Figure 3. Langmuir adsorption isotherm for BDAB, PDAB and HDAB on mild steel surface. enthalpy of adsorption, $\Delta \mathrm{H}$ and entropy of adsorption, $\Delta \mathrm{S}$ for the corrosion of mild steel in $20 \%$ formic acid in presence of gemini surfactants was obtained by the Equation 6:

$\mathrm{CR}=\frac{\mathrm{RT}}{\mathrm{Nh}} \exp \left(\frac{\Delta \mathrm{S}}{\mathrm{R}}\right) \exp \left(-\frac{\Delta \mathrm{H}}{\mathrm{RT}}\right)$

where N is the Avogadro's number, h is the Planck's constant, $\mathrm{R}$ is the molar gas constant and $\mathrm{T}$ is the absolute temperature. Figure 5 shows the plot of $\log (\mathrm{CR} / \mathrm{T})$ versus $1 / \mathrm{T}$ for blank and the three surfactants. Linear plot was obtained and from

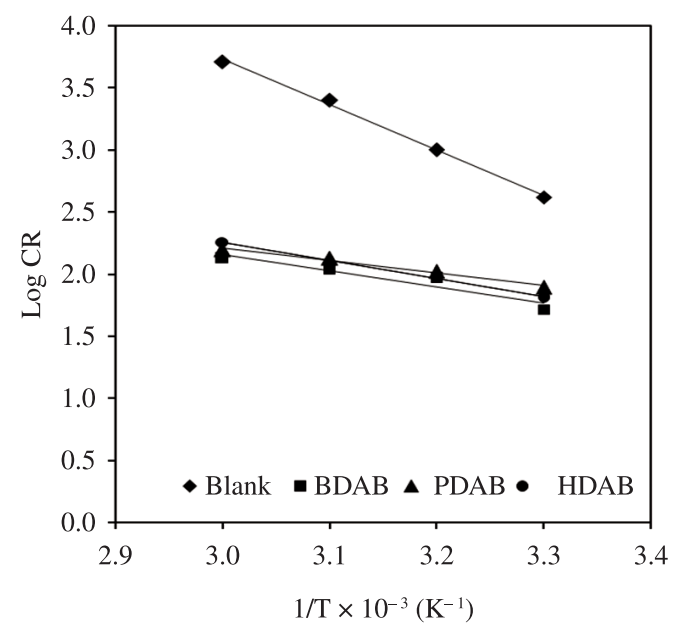

Figure 4. Adsorption isotherm plot for $\log \mathrm{CR}$ vs $1 / \mathrm{T}$ in absence and presence of inhibitors.

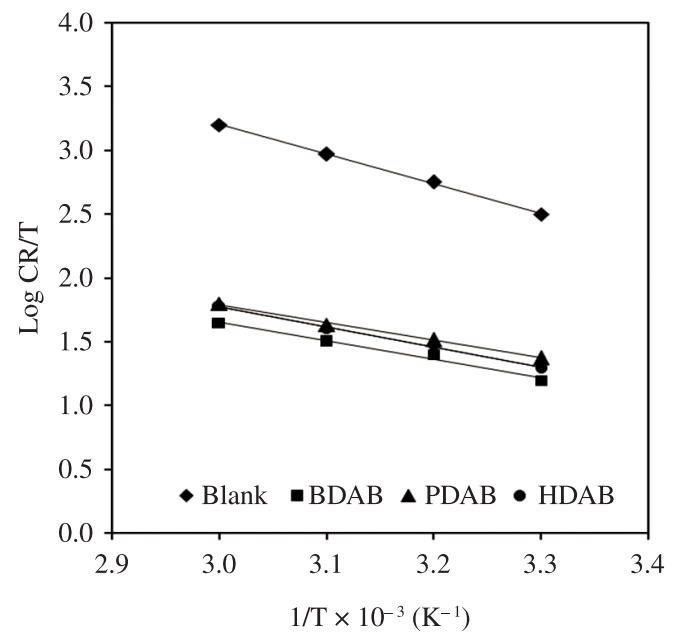

Figure 5. Adsorption isotherm plot for $\log \mathrm{CR} / \mathrm{T}$ vs $1 / \mathrm{T}$ in the absence and presence of inhibitors.

Table 3. Parameters from Langmuir adsorption isotherm, value of $\mathrm{K}$ at different temperatures.

\begin{tabular}{cccccc}
\hline Surfactants & $\mathbf{R}^{\mathbf{2}}$ & \multicolumn{4}{c}{$\mathbf{K} \times \mathbf{1 0}^{\mathbf{3}}$} \\
\hline & & $\mathbf{3 0}^{\circ} \mathbf{C}$ & $\mathbf{4 0}^{\circ} \mathbf{C}$ & $\mathbf{5 0}^{\circ} \mathbf{C}$ & $\mathbf{6 0}^{\circ} \mathbf{C}$ \\
\hline BDAB & 0.999 & 11.33 & 31.33 & 48.00 & 64.67 \\
PDAB & 1 & 8.53 & 26.57 & 38.00 & 64.67 \\
HDAB & 0.999 & 11.33 & 31.33 & 48.00 & 64.67 \\
\hline
\end{tabular}


the slope $\left(-\frac{\Delta H}{2.303 R T}\right)$ and intercept $\left[\log \left(\frac{R}{N h}\right)+\left(\frac{\Delta S}{2.303 R}\right)\right]$ of the linear plot, the values of $\Delta \mathrm{H}$ and $\Delta \mathrm{S}$, respectively, were obtained. The calculated values are presented in Table 4 . The enthalpy of adsorption decreases in presence of the gemini surfactants compared to the free acid solution, this further support the mechanism of chemisorption. The values of $\Delta S$ are negative which indicates an increase in the system order in the presence of surfactants ${ }^{37}$. Figure 6 shows a plot of $\log \left(\frac{\theta}{1-\theta}\right)$ versus $1 / \mathrm{T}$ for the surfactants. Linear plot was obtained and from the slope $\left[\frac{-Q}{2.303 R}\right]$ of the linear plot, heat of adsorption, $\mathrm{Q}_{\mathrm{ads}}$ was obtained. The calculated values of $\mathrm{Q}_{\mathrm{ads}}$ were positive (Table 4) indicating that the adsorption of gemini surfactants on mild steel surface is endothermic. The free energy of adsorption, $\Delta \mathrm{G}_{\text {ads }}$ was obtained from the intercept of plot of log inhibition efficiency (log \% IE) versus $\log$ inhibitor concentration $(\log \mathrm{C})$ and evaluated using the following Equation $7^{38}$ :

$\log C=\log \left(\frac{\theta}{1-\theta}\right)-\log B$

where, $\log B=-1.74-\left(\frac{\Delta G_{a d s}}{2.303 R T}\right)$ and $\mathrm{C}$, is the concentration of the system studied. The calculated values of $\Delta \mathrm{G}_{\text {ads }}$ from 30 to $60^{\circ} \mathrm{C}$ for each gemini surfactants are presented in Table 4 . The negative values of $\Delta \mathrm{G}_{\text {ads }}$ indicate the spontaneous adsorption of the gemini surfactants on the mild steel surface. The values of $\Delta \mathrm{G}_{\text {ads }}$ obtained in this study are more negative than $-20 \mathrm{KJ} \cdot \mathrm{mol}^{-1}$ (between -26.94 .96 and $-41.79 \mathrm{KJ} . \mathrm{mol}^{-1}$ ). This is consistent with charge sharing or transfer from the inhibitor molecules to the metal surface to form a coordinate type of bond indicating chemical adsorption ${ }^{38-40}$.

\subsection{Solution analysis of metal ion}

The corrosion rate of mild steel in $20 \%$ formic acid in absence and presence of gemini surfactants at $30-60{ }^{\circ} \mathrm{C}$ was also measured by determining the total iron ions entered into the test solution during the course of immersion and the result is shown in Table 5. The \%IE obtained by solvent analysis is consistent with \%IE determined by weight loss measurements.

\subsection{Potentiodynamic polarization measurements}

The potentiodynamic polarization curves for the corrosion of mild steel in $20 \%$ formic acid in absence and presence of varying concentrations of gemini surfactants are shown in (Figure 7). The values of electrochemical parameters as deduced from the curves e.g., corrosion potential $\left(\mathrm{E}_{\text {corr }}\right)$, corrosion current density $\left(\mathrm{I}_{\text {corr }}\right)$, anodic tafel slope $\left(\beta_{\mathrm{a}}\right)$, cathodic tafel slope $\left(\beta_{\mathrm{c}}\right)$, corrosion rate and \% IE are shown in Table 6 .The \% IE was calculated using the following Equation 8:

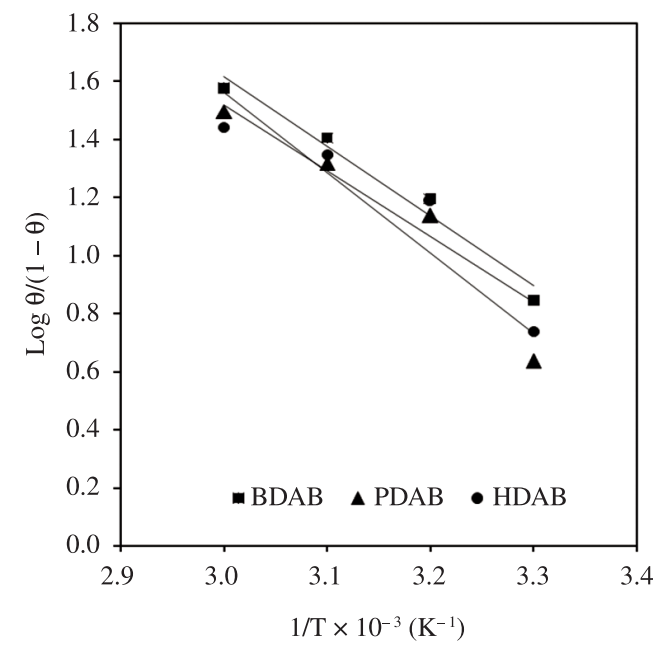

Figure 6. Adsorption isotherm plot for $\log (\theta / 1-\theta)$ in the absence and presence of inhibitors.

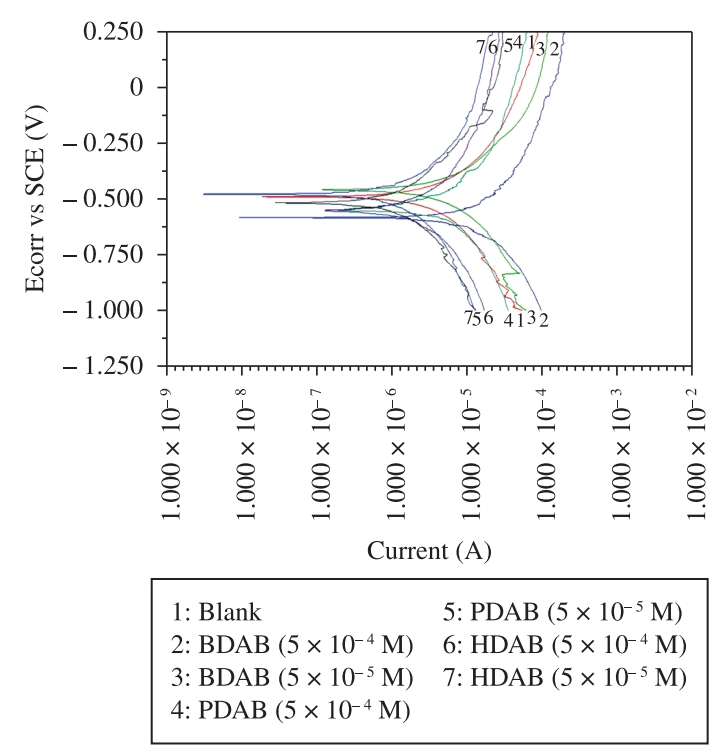

Figure 7. Potentiodynamic curves for mild steel in $20 \%$ formic acid in absence and presence of different concentration of inhibitors (1) Blank (2) BDAB $\left(5 \times 10^{-4}\right)$, (3) BDAB $\left(5 \times 10^{-5}\right)$, (4) PDAB $\left(5 \times 10^{-4}\right),(5) \mathrm{PDAB}\left(5 \times 10^{-5}\right),(6) \mathrm{HDAB}\left(5 \times 10^{-4}\right),(7) \mathrm{HDAB}$ $\left(5 \times 10^{-5}\right)$.

Table 4. Calculated values of kinetic/thermodynamic parameters for mild steel in $20 \%$ formic acid in the absence and presence of gemini surfactants from weight loss measurement.

\begin{tabular}{|c|c|c|c|c|c|c|c|c|}
\hline \multirow{2}{*}{ Surfactants } & \multirow{2}{*}{$\begin{array}{c}\mathbf{E a} \\
\left(\mathbf{k J} . \mathrm{mol}^{-1}\right)\end{array}$} & \multirow{2}{*}{$\begin{array}{c}\Delta \mathbf{H} \\
\left(\mathbf{k J} . \mathrm{mol}^{-1}\right)\end{array}$} & \multirow{2}{*}{$\begin{array}{c}\Delta S \\
\left(\mathrm{~kJ} . \mathrm{mol}^{-1}-\mathrm{K}\right)\end{array}$} & \multirow{2}{*}{$\begin{array}{c}\mathbf{Q} \\
\left(\mathbf{k J} . \mathrm{mol}^{-1}\right)\end{array}$} & \multicolumn{4}{|c|}{$\Delta \mathbf{G}_{\text {ads }}\left(\mathbf{k J} \cdot \mathrm{mol}^{-1}\right)$} \\
\hline & & & & & $30^{\circ} \mathrm{C}$ & $40{ }^{\circ} \mathrm{C}$ & $50{ }^{\circ} \mathrm{C}$ & $60^{\circ} \mathrm{C}$ \\
\hline BLANK & 51.33 & 44.23 & -4.02 & - & - & - & - & - \\
\hline BDAB & 15.8 & 21.94 & -83.04 & 45.88 & -33.64 & -26.94 & -28.95 & -30.67 \\
\hline PDAB & 17.28 & 26.75 & -83.79 & 52.85 & -32.93 & -36.95 & -39.10 & -41.79 \\
\hline HDAB & 27.58 & 30.65 & -72.36 & 43.50 & -33.64 & -37.39 & -39.79 & -41.79 \\
\hline
\end{tabular}


$\% \mathrm{IE}=\frac{i_{\text {corr }}^{o}-i_{\text {corr }}}{i_{\text {corr }}^{o}} \times 100$

where $i_{\text {corr }}^{o}$ and $i_{\text {corr }}$ are the corrosion current density in absence and presence of surfactants, respectively. The study of electrochemical data reveals that the values of $i_{\text {cor }}$ decreases in presence of gemini surfactants. There was a change in the values of both anodic and cathodic tafel slopes indicating that inhibition action was under both anodic and cathodic control. In presence of surfactants the shift in $\mathrm{E}_{\text {corr }}$ was less than $85 \mathrm{mV}$, indicating that all the three surfactants behaves as mixed type inhibitors ${ }^{41,42}$. The values of $\%$ IE obtained from electrochemical and weight loss methods remain different, this may be due to the fact that \% IE obtained from electrochemical method is an instantaneous value while, \%IE calculated from weight loss method is an average value. However, the electrochemical results on a whole are in good agreement with weight loss results.

\subsection{Morphological study of mild steel}

The surface images of the mild steel and steel surface exposed to uninhibited and inhibited acid solution are shown in Figure 8. The mild steel surface exposed to inhibited acid solution was found to be smoother than the one exposed to uninhibited acid solution. This is due to the adsorbed surfactant molecules which prevented the corrosion of steel. This confirms the active role of the synthesized surfactants in corrosion inhibition.

Table 5. Calculated values of corrosion rate and inhibition efficiency for mild steel in $20 \%$ formic acid in absence and presence of Gemini surfactants at $30-60{ }^{\circ} \mathrm{C}$ from weight loss measurement from solvent analysis of iron ions into test solution.

\begin{tabular}{|c|c|c|c|c|c|c|c|c|}
\hline \multirow{2}{*}{$\begin{array}{c}\text { Surfactant } \\
\text { concentration }(M)\end{array}$} & \multicolumn{4}{|c|}{ Corrosion rate $\left(\mathrm{gm}^{-2} \mathbf{h}^{-1}\right)$} & \multicolumn{4}{|c|}{ Inhibition Efficiency (IE) } \\
\hline & $30{ }^{\circ} \mathrm{C}$ & $40{ }^{\circ} \mathrm{C}$ & $50{ }^{\circ} \mathbf{C}$ & $60{ }^{\circ} \mathrm{C}$ & $30{ }^{\circ} \mathbf{C}$ & $40{ }^{\circ} \mathrm{C}$ & $50{ }^{\circ} \mathbf{C}$ & $60{ }^{\circ} \mathrm{C}$ \\
\hline Blank & 1.400 & 1.900 & 1.960 & 3.120 & - & - & - & - \\
\hline \multicolumn{9}{|l|}{ BDAB } \\
\hline $1 \times 10^{-5}$ & 0.211 & 0.160 & 0.127 & 0.156 & 84.93 & 91.58 & 93.50 & 95.00 \\
\hline $5 \times 10^{-5}$ & 0.175 & 0.180 & 0.116 & 0.165 & 87.50 & 90.53 & 94.10 & 94.70 \\
\hline $1 \times 10^{-4}$ & 0.172 & 0.120 & 0.098 & 0.156 & 87.70 & 93.68 & 95.00 & 95.00 \\
\hline $5 \times 10^{-4}$ & 0.153 & 0.160 & 0.084 & 0.119 & 89.10 & 91.58 & 95.80 & 96.20 \\
\hline $1 \times 10^{-3}$ & 0.185 & 0.200 & 0.157 & 0.125 & 86.80 & 89.50 & 91.98 & 96.00 \\
\hline \multicolumn{9}{|l|}{ PDAB } \\
\hline $1 \times 10^{-5}$ & 0.280 & 0.180 & 0.176 & 0.188 & 81.25 & 90.00 & 91.11 & 93.97 \\
\hline $5 \times 10^{-5}$ & 0.260 & 0.144 & 0.180 & 0.192 & 81.90 & 92.00 & 91.00 & 93.85 \\
\hline $1 \times 10^{-4}$ & 0.230 & 0.176 & 0.167 & 0.180 & 84.03 & 90.22 & 91.50 & 94.23 \\
\hline $5 \times 10^{-4}$ & 0.200 & 0.160 & 0.156 & 0.156 & 86.11 & 91.11 & 92.04 & 95.00 \\
\hline $1 \times 10^{-3}$ & 0.240 & 0.160 & 0.132 & 0.190 & 83.33 & 91.11 & 93.2 & 93.91 \\
\hline \multicolumn{9}{|l|}{ HDAB } \\
\hline $1 \times 10^{-5}$ & 0.392 & 0.140 & 0.137 & 0.184 & 74.30 & 92.63 & 93.00 & 94.10 \\
\hline $5 \times 10^{-5}$ & 0.456 & 0.128 & 0.125 & 0.190 & 70.00 & 93.26 & 93.60 & 93.90 \\
\hline $1 \times 10^{-4}$ & 0.448 & 0.144 & 0.118 & 0.181 & 70.53 & 92.42 & 94.00 & 94.20 \\
\hline $5 \times 10^{-4}$ & 0.395 & 0.112 & 0.092 & 0.159 & 74.00 & 94.12 & 95.31 & 94.90 \\
\hline $1 \times 10^{-3}$ & 0.377 & 0.136 & 0.108 & 0.165 & 75.20 & 92.84 & 94.50 & 94.70 \\
\hline
\end{tabular}

Table 6. Potentiodynamic polarization parameters for corrosion of mild steel in $20 \%$ formic acid in the absence and presence of gemini surfactants concentration at $30^{\circ} \mathrm{C}$.

\begin{tabular}{|c|c|c|c|c|c|c|}
\hline $\begin{array}{l}\text { Surfactant concentration } \\
\text { (M) }\end{array}$ & $\mathbf{E}_{\text {corr }}(\mathbf{V})$ & $I_{\text {corr }}\left(\mathrm{A} \mathrm{cm}^{-2}\right) \times 10^{-6}$ & $\beta \mathbf{a}(\mathrm{V} / \mathrm{dec})$ & $\beta_{\mathrm{c}}(\mathrm{V} / \mathrm{dec})$ & $\mathrm{CR}(\mathrm{mpy}) \times 10^{-2}$ & $\%$ IE \\
\hline BLANK & -0.492 & 6.973 & 0.4201 & 0.6528 & 319.42 & - \\
\hline \multicolumn{7}{|l|}{ BDAB } \\
\hline $5 \times 10^{-4}$ & -0.498 & 0.719 & 0.13 & 0.045 & 32.94 & 89.69 \\
\hline $5 \times 10^{-5}$ & -0.451 & 2.561 & 0.1647 & 0.1597 & 117.33 & 63.27 \\
\hline \multicolumn{7}{|l|}{ PDAB } \\
\hline $5 \times 10^{-4}$ & -0.554 & 0.017 & 0.0486 & 0.0227 & 0.78 & 99.76 \\
\hline $5 \times 10^{-5}$ & -0.526 & 0.143 & 0.0544 & 0.0179 & 6.54 & 97.95 \\
\hline \multicolumn{7}{|l|}{ HDAB } \\
\hline $5 \times 10^{-4}$ & -0.53 & 0.400 & 0.0532 & 0.0793 & 18.30 & 94.27 \\
\hline $5 \times 10^{-5}$ & -0.48 & 0.451 & 0.1213 & 0.0594 & 20.67 & 93.53 \\
\hline
\end{tabular}




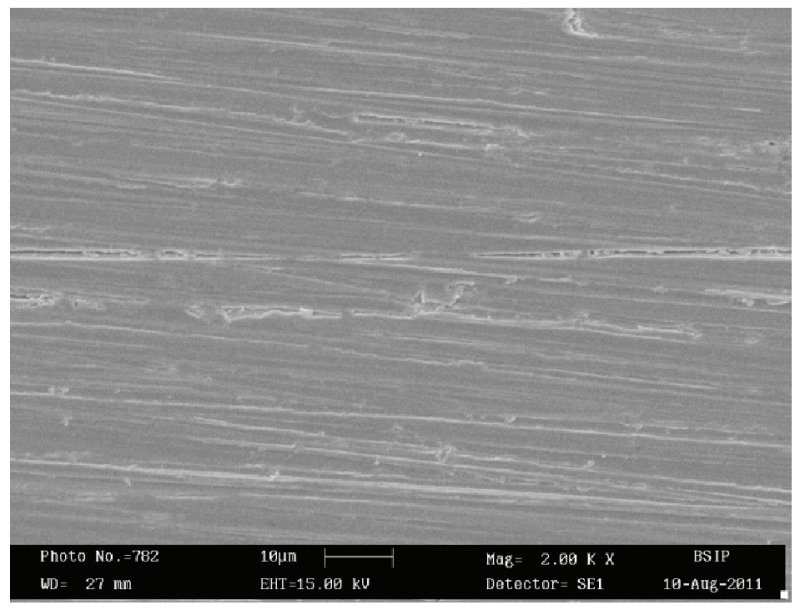

(a)

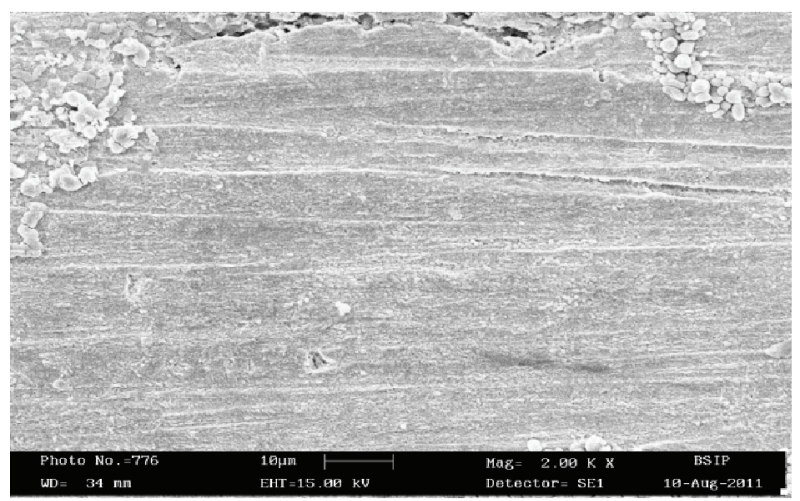

(c)

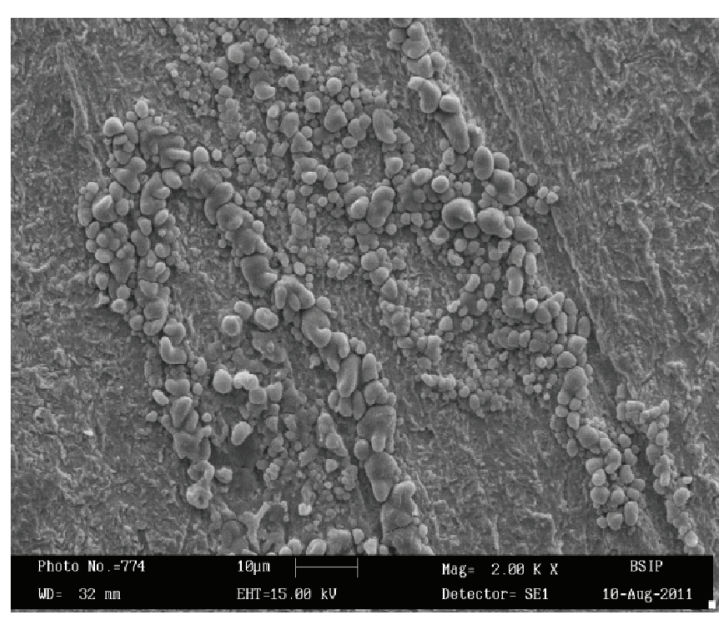

(b)

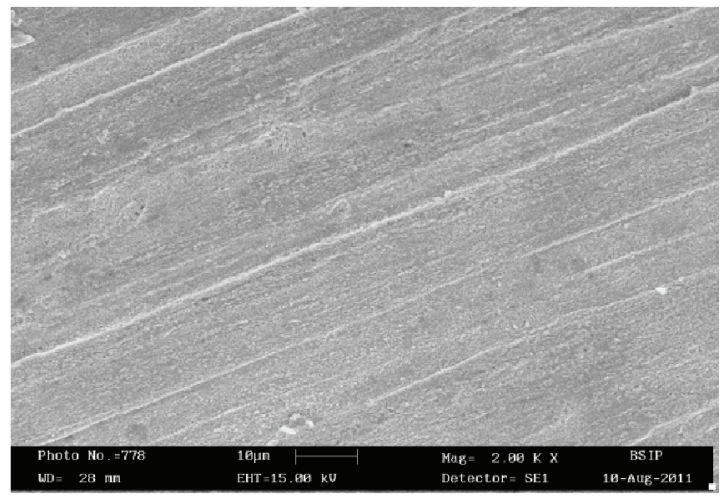

(d)

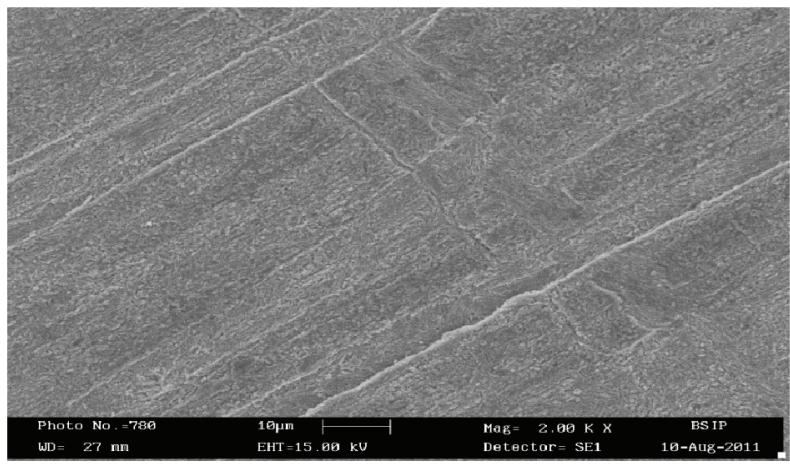

(e)

Figure 8. Morphological study of mild steel sample a) Polished, b) dipped in $20 \%$ formic acid, c) dipped in $20 \%$ formic acid containing $5 \times 10^{-4} \mathrm{BDAB}, \mathrm{d}$ ) dipped in $20 \%$ formic acid containing $5 \times 10^{-4} \mathrm{PDAB}, \mathrm{e}$ ) dipped in $20 \%$ formic acid containing $5 \times 10^{-4} \mathrm{HDAB}$.

\section{Conclusions}

The synthesized gemini surfactants showed good performance as corrosion inhibitors for mild steel in $20 \%$ formic acid. The inhibition behavior is slightly affected by the spacer length of the surfactants. The phenomenon of chemical adsorption was proposed from the trend of inhibition efficiency with temperature. The weight loss data suggest corrosion inhibition by adsorption mechanism and fits well to the Langmuir adsorption isotherm at various concentrations and temperatures studied. The results of potentiodynamic polarization measurements showed that gemini surfactants acts a mixed type inhibitors. The SEM studies showed smoother surface for inhibited steel.

\section{Acknowledgements}

One of the authors (Sheerin Masroor) thankfully acknowledges the financial assistance from U.G.C., New Delhi. 


\section{References}

1. Popova A, Christov M and Vasilev A. Mono- and dicationic benzothiazolic quaternary ammonium bromides as mild steel corrosion inhibitors. Part II: Electrochemical impedance and polarisation resistance results. Corrosion Science. 2011; 53:1770-1777. http://dx.doi.org/10.1016/j. corsci.2011.01.055

2. Xianghon L, Shuduan D and Hui F. Triazolyl blue tetrazolium bromide as a novel corrosion inhibitor for steel in $\mathrm{HCl}$ and $\mathrm{H}_{2} \mathrm{SO}_{4}$ solutions. Corrosion Science. 2011; 53:302-309. http:// dx.doi.org/10.1016/j.corsci.2010.09.036

3. Migahed MA, Aly RO and Al-Sabagh AM. Impact of gamma-ray-pre-irradiation on the efficiency of corrosion inhibition of some novel polymeric surfactants. Corrosion Science. 2004; 46:2503-2516. http://dx.doi.org/10.1016/j. corsci.2004.01.013

4. Migahed MA, Abd-El-Raouf MA, Al-Sabagh AM and Abd-El-Bary HM. Effectiveness of some non ionic surfactants as corrosion inhibitors for carbon steel pipelines in oil fields. Electrochimica Acta. 2005; 50:4683-4689. http://dx.doi. org/10.1016/j.electacta.2005.02.021

5. Frignani A, Zucchi $\mathrm{F}$ and Monticelli C. Inhibition of iron corrosion in different acid media by N-Decyl- Pyridinium derivatives. British Corrosion Journal. 1983; 18:19-24. http:// dx.doi.org/10.1179/000705983798274029

6. Ghosh PK, Guhasarkar DK and Gupta VS. Inhibition of corrosion of mild steel in hydrochloric acid at higher temperatures by amidopolyamines. British Corrosion Journal. 1983; 18:187-189. http://dx.doi.org/10.1179/000705983798273679

7. Zucchi F, Trabanelli G and Brunoro G. Iron corrosion inhibition in hot $4 \mathrm{M} \mathrm{HCl}$ solution by t-cinnamaldehyde and its structurerelated compounds. Corrosion Science. 1994; 36:1683-1690. http://dx.doi.org/10.1016/0010-938X(94)90123-6

8. Frenier WW, Growcock FB and Lopp VR. $\alpha$-Alkenylphenones - A New Class of Acid Corrosion Inhibitors. Corrosion. 1988; 44:590-598. http://dx.doi. org/10.5006/1.3584970

9. Quraishi MA and Jamal D. Dianils: New and Effective Corrosion Inhibitors for Oil-Well Steel (N-80) and Mild Steel in Boiling Hydrochloric Acid. Corrosion. 2000; 56:156-160. http://dx.doi.org/10.5006/1.3280531

10. Bentiss F, Traisnel $M$ and Lagrenee $M$. The substituted 1,3,4-oxadiazoles: a new class of corrosion inhibitors of mild steel in acidic media. Corrosion Science. 2000; 42:127-146. http://dx.doi.org/10.1016/ S0010-938X(99)00049-9

11. Kertit $\mathrm{S}$ and Hammouti B. Corrosion inhibition of iron in $1 \mathrm{M} \mathrm{HCl}$ by 1 -phenyl-5-mercapto-1,2,3,4-tetrazole. Applied Surface Science. 1996; 93:59-66. http://dx.doi. org/10.1016/0169-4332(95)00189-1

12. Suchmitt G. Application of inhibitors for acid media. British Corrosion Journal. 1984; 19:165-176.

13. Heitz E. Corrosion of metals in organic solvents. New York: Plenum Press; 1974. 226 p.

14. Singh VB and Singh RN. Corrosion and inhibition studies of copper in aqueous solutions of formic acid and acetic acid. Corrosion Science. 1995; 37:1399-1410. http://dx.doi. org/10.1016/0010-938X(95)00042-I

15. Singh MM and Gupta A. Corrosion behaviour of mild steel in formic acid solutions. Materials Chemistry and Physics. 1996; 46:15-22. http://dx.doi. org/10.1016/0254-0584(96)80124-6
16. Garverich L. Corrosion in petrochemical industry. ASM International; 1994. p. 197.

17. Frignani A, Tassinari M, Meszaros L and Trabanelli G. The use of electrochemical impedance spectroscopy to study ARMCO iron corrosion in acid solutions inhibited by quaternary ammonium compounds. Corrosion Science. 1991; 32:903-911. http://dx.doi.org/10.1016/0010-938X(91)90033-L

18. Hajjaji N, Ricco I, Srhiri A, Lattes A, Scufiaoui M and Bachir AB. Effect of N-Alkylbetaines on the Corrosion of Iron in 1 M HCl Solution. Corrosion. 1993; 49:326-334. http://dx.doi. org/10.5006/1.3316057

19. AchouriME, Hajji MS, KertitS, EssassiEM, Salem Mand Coudert R. Some surfactants in the series of 2-(alkyldimethylammonio) alkanol bromides as inhibitors of the corrosion of iron in acid chloride solution. Corrosion Science. 1995; 37:381-389. http:// dx.doi.org/10.1016/0010-938X(94)00134-R

20. Mobin M, Khan MA and Parveen M. Inhibition of mild steel corrosion in acidic medium using starch and surfactants additives. Jornal of Applied Polymer Science. 2011; 121:1558-1565. http://dx.doi.org/10.1002/app.33714

21. Rafiquee MZA, Saxena N, Khan S and Quraishi MA. Influence of surfactants on the corrosion inhibition behaviour of 2-aminophenyl-5-mercapto-1-oxa-3,4-diazole (AMOD) on mild steel. Materials Chemistry and Physics. 2008; 107:528-533. http://dx.doi.org/10.1016/j.matchemphys.2007.08.022

22. Reyes Y, Rodriguez FJ, del Rio JM, Corea M and Vazuez F. Characterisation of an anticorrosive phosphated surfactant and its use in water-borne coatings. Progress in Organic Coatings. 2005; 52:366-371. http://dx.doi.org/10.1016/j. porgcoat.2004.09.008

23. Migahed MA and Al-Sabagh AM. Beneficial role of surfactants as corrosion inhibitors in petroleum industry: a review article. Chemical Engineering Communications. 2009; 196:1054-1075. http://dx.doi.org/10.1080/00986440902897095

24. Free ML. Development and Application of Useful Equations to Predict Corrosion Inhibition by Different Surfactants in Various Aqueous Environments. Corrosion. 2002; 58:1025-1030. http:// dx.doi.org/10.5006/1.3280791

25. Wang WL and Free ML. Prediction and measurement of corrosion inhibition of mild steel using nonionic surfactants in chloride media. Corrosion Science. 2004; 46:2601-2611. http://dx.doi.org/10.1016/S0010-938X(03)00152-5

26. Saleh M and Atha AA. Effect of structure of the ionic head of cationic surfactant on its inhibition of acid corrosion of mild steel. Journal of Applied Electrochemistry. 2006; 36:899-905.

27. Ansari FA and Quraishi MA. Inhibitive Performance of Gemini Surfactants as Corrosion Inhibitors for Mild Steel in Formic Acid. Portugaliae Electrochimica Acta. 2010; 28(5):321-335. http://dx.doi.org/10.4152/pea.201005321 http://dx.doi. org/10.4152/pea.201005321

28. Sharma HK and Quraishi MA. Inhibitive effect of some gemini surfactants on mild steel corrosion in acid solutions. Indian Journal Of Chemical Technology. 2007; 14:494-500.

29. Ansari FA and Quraishi MA.Inhibitive effect of some gemini surfactants as corrosion inhibitors for mild steel in acetic acid media. Arabian Journal for Science and Engineering. 2011; 36:11-20. http://dx.doi.org/10.1007/ s13369-010-0008-6

30. De S, Aswal VK, Goyal PS and Bhattacharya S. Role of Spacer Chain Length in Dimeric Micellar Organization. Small Angle Neutron Scattering and Fluorescence Studies. The Journal of Physical Chemistry. 1996; 100:11664-11671. http://dx.doi. org/10.1021/jp9535598 
31. Kabir-ud-Din, Fatma W and Khan ZA. A ${ }^{1} \mathrm{H}$ NMR study of 1,4 bis (N-Hexadecyl-N,N-dimethyl ammonium) butane dibromide/sodium anthranilate system:spherical to rod shaped transition. Colloid and Polymer Science. 2006; 284:1339-1344.

32. Mobin M and Tanveer N. Corrosion Behavior of Chemically Deposited Single and Bi-layered Conducting Polymer Coatings on Mild Steel. Portugaliae Electrochimica Acta. 2011; 29(3):139-154. http://dx.doi.org/10.4152/ pea.201103139

33. Mobin M and Tanveer N. Corrosion performance of chemically synthesized poly(aniline-co-o-toluidine) copolymer coating on mild steel. Journal of Coatings Technology and Research. 2012; 9:27-38. http://dx.doi.org/10.1007/ s11998-011-9328-Z

34. Qui LG, Xie AJ and Shen YH. Understanding the adsorption of cationic gemini surfactants on steel surface in hydrochloric acid. Materials Chemistry and Physics. 2004; 87:237-240. http://dx.doi.org/10.1016/j.matchemphys.2004.06.014

35. Huan W and Zhao J. Adsorption of quaternary ammonium gemini surfactants on zinc and the inhibitive effect on zinc corrosion in vitriolic solution. Colloids and Surfaces A: Physicochemical and Engineering Aspects. 2006; 278:246-251. http://dx.doi.org/10.1016/j.colsurfa.2005.12.028

36. Refray SAM, Taha F and Abd-El-MalakAM. Inhibition of stainless steel pitting corrosion in acidic medium by 2 -mercaptobenzoxazole.
Applied Surface Science. 2004; 236:175-185. http://dx.doi. org/10.1016/j.apsusc.2004.04.016

37. Umoren SA, Ogbobe O, Igwe IO and Ebenso EE. Inhibition of mild steel corrosion in acidic medium using synthetic and naturally occurring polymers and synergistic halide additives. Corrosion Science. 2008; 50:1998-2006. http://dx.doi. org/10.1016/j.corsci.2008.04.015

38. Bilgic $\mathrm{S}$ and Sahin M. The corrosion inhibition of austenitic chromium-nickel steel in $\mathrm{H}_{2} \mathrm{SO}_{4}$ by 2-butyn-1-ol. Materials Chemistry Physics. 2001; 70:290-295. http://dx.doi. org/10.1016/S0254-0584(00)00534-4

39. Ebenso EE. Synergistic effect of halide ions on the corrosion inhibition of aluminium in $\mathrm{H}_{2} \mathrm{SO}_{4}$ using 2-acetylphenothiazine. Materials Chemistry Physics. 2003; 79:58-70. http://dx.doi. org/10.1016/S0254-0584(02)00446-7

40. Bhajiwala HM, Vashi RT. Ethanolamine, diethanolamine and triethanolamine as corrosion inhibitors for zinc in binary acid mixture $\left[\mathrm{HNO}_{3}+\mathrm{H}_{3} \mathrm{PO}_{4}\right]$. Bulletin of Electrochemistry. 2001; 17:441-448.

41. Riggs OL. Corrosion. 1975; 31:128.

42. Ferreira ES, Giancomelli C, Giacomelli FC and Spinelli A. Evaluation of the inhibitor effect of 1-ascorbic acid on the corrosion of mild steel. Materials Chemistry Physics. 2004; 83:129-134. http://dx.doi.org/10.1016/j. matchemphys.2003.09.020 